\title{
Green Sensitive Consumer Demand and Government Subsidy as Drivers of Product Green Innovation
}

\author{
Hui Zhou \\ College of Modern Economic \& Management, Jiangxi University of Finance and Economics, P.R. China
}

\begin{abstract}
We study the drives of green sensitive consumer demand and government subsidy to product green innovation. In a monopolistic market with linear demand, a firm produces and sells its product to consumers. In the benchmark, demand depends only on price, and then consumer's green sensitivity was introduced to analyze the change of price and profit. At last, decisions on pricing and green degree were investigated under the setting of green sensitive consumer demand and government subsidy. We find that, considering green sensitivity of consumers benefits the firm and is helpful to product green innovation; product price is decreasing in the government subsidy, and the green degree selected by the firm with government subsidy is higher than the case without.
\end{abstract}

Keywords-green innovation; green sensitive consumer demand; government subsidy; green degree

\section{INTRODUCTION}

Natural disasters have been frequent and the deterioration of the ecological environment has become one of the most serious challenges facing mankind in the 21st century. Environmental protection has aroused widespread concern in the world. Dangelico and Pontrandolfo point out that production of green products is not only requirements of laws and regulations, competition and ecological responsibility, but also an opportunity for enterprises to meet the needs of consumer market [1]. A large number of literatures show that, more and more people concern about environment in developed and developing countries, especially young people, which increases demand of green products, improves consumer's environmental awareness, and changes consumer purchase behavior greatly [2-4]. There is evidence that green sensitive consumers are willing to pay for extra cost of green products, and companies may also improve environment at the same time by enhancing green degree of the product to increase profits [5]. For example, Toyota's hybrid Prius is 50\% more expensive than the same-powered petrol truck, but is the fifth in Japan's new car sales in 2008. In transportation services (such as hybrids), environmentally friendly green product can increase the utility of green sensitive consumers [6]. In the initial stage, a large amount of money is needed to production greening. In order to relieve the problem of financing, government usually provide subsidies for the firm to prompt the production of green products, such as electric vehicle $[7,8]$.There are two reasons for the firm to green innovation. On the one hand, green sensitive consumer demand drives the firm to innovate its products, which induce the firm get more market. On the other hand, a vast government subsidy for manufacturing green product is attractive to the firm. It can acquire more revenue as well as better goodwill by green innovation.

Based on this background, we address the question by developing an analysis in which a manufacturer faces green sensitive consumer and (or) government subsidy to invest to green his product. The rest of this paper is organized as follow. In next section, we present the main assumptions and setup of the basic model, which is a benchmark for analysis. In section III, green sensitive consumer demand is introduced in the model to analyze the change in profit. In section IV, both green sensitive consumer demand and government subsidy are considered in the model to investigate decisions on pricing and green degree of the product. Section V concludes.

\section{THE BASIC MODEL}

Consider a monopolistic channel where a single firm produces and sells its non-green product to consumers. Assuming the demand $(q)$ faced by consumers is a linear function of market price $(p)$, the demand function is given as

$$
q=a-b p \quad \text { where } a>b p, a, b>0
$$

In this function, $a$ is the amount of market potential, $b$ is the sensitivity of consumers to the firm's price. Also, we suppose per unit cost of the product is $c$, and the fixed cost is zero. Based on the assumptions above, the firm's profit function is

$$
\Pi_{N}(p)=(a-b p)(p-c)
$$

The subscript $N$ denotes the case of no consumer sensitivity and no subsidy. By computing the first order conditions, it is straightforward to obtain the firm's profit-maximizing price

$$
p_{N}^{*}=\frac{a}{2 b}+\frac{c}{2}
$$

Substituting the value of $p_{N}^{*}$ into the firm's profit function, we gain the maximum profit is

$$
\Pi_{N}^{*}=\frac{(a-b c)^{2}}{4 b}
$$

The equilibrium quantity is

$$
q_{N}^{*}=\frac{a-b c}{2}
$$




\section{AnAlysis Under GREen SENSITIVE CONSUMER DEMAND}

In this section, we will investigate product green innovation under green sensitive consumer demand. According to $[9,10]$, we introduce green degree of the product and consumers' sensitivity into demand function. Demand function is given as

$$
d=a-b p+k g
$$

In this function, $g$ is green degree of the product, and $k$ is the sensitivity of consumers to the green degree. The meanings of a and $b$ are the same as in section II. To be specific, the demand function reflects that, in a green sensitive market, demand is linearly decreasing in the product price and increasing in green degree of the product produced. As the green degree increases, its demand increases by an amount $\mathrm{kg}$, and the value of $k$ shows the extent of changes. Although $k$ means how much green consumers care about the green degree, in order to guarantee further analysis, we presume that $k$ is exogenous and cannot be influenced by the firm, so it is outside the firm's control. We suppose that $k$ is influenced by external factors such as public service advertising, environmental awareness and forcing by new rules. For example, raising electricity price my lead consumers to choose energy-efficient equipment, which will improve the value of $k$. When $b>k$, the sensitivity of consumers to price is more than to green degree, in other words, consumers will put more weights in price than green degree when making a purchase. Otherwise, the effect is opposite.

In order to green the product or raise green degree through green innovation, the firm need to invest, such as using advanced production technologies or cleaner technologies. Referring to Ghosh[9], there is an increasing and convex cost structure in improving green degree. The cost of greening is given by $I g^{2}$ where $I$ indicates the magnitude of the cost involved in green innovation. That is to say, raising green degree might be relatively inexpensive in the initial stages, as the green degree improves, more managerial and technological investment are required for further improvement in green degree, making it more expensive to reach the goal of higher green degree comparable to the early stage. We also assume that greening improvement does not affect the firm's variable cost of per unit, so that the model is in a tractable form.

To make sure that there is a reasonable solution in the analysis behind, we assume that $I>k^{2} /(4 b)$. That is to say, given consumers' sensitivity to the green degree and the price, green innovation requires higher investment, which is consistent with the actual situation of product innovation.

In this situation, the firm's profit function is given by

$$
\Pi_{S}(p, g)=(a-b p+k g)(p-c)-I g^{2}
$$

The subscript $S$ denotes the case of considering consumer sensitivity. The function shows that profit is determined by price and green degree of the product.

Proposition 1. Considering green sensitive consumer demand, both the market price and firm's profit are increased; price and profit are increased with green sensitivity of the consumers.

Proof: The first order derivatives of the profit function are

$$
\begin{gathered}
\frac{\partial \Pi_{S}}{\partial p}=a-2 b p+k g+b c \\
\frac{\partial \Pi_{S}}{\partial g}=k(p-c)-2 I g
\end{gathered}
$$

Equating the two derivatives to 0 and solving the equations, when $4 b I>k^{2}$ we derive

$$
\begin{gathered}
g_{S}^{*}=\frac{k(a-b c)}{4 b I-k^{2}} \\
p_{S}^{*}=\frac{2 I(a-b c)}{4 b I-k^{2}}+c
\end{gathered}
$$

We substitute the values of $g_{S}^{*}$ and $p_{S}^{*}$ into the equation (6) and derive the demand of the product

$$
q_{S}^{*}=\frac{I(a-b c)^{2}}{4 b I-k^{2}}
$$

Substituting $g_{S}^{*}$ and $p_{S}^{*}$ into $\Pi_{S}$, we obtain

$$
\Pi_{S}^{*}=\frac{I(a-b c)^{2}}{4 b I-k^{2}}
$$

Because $\quad p_{S}^{*}-p_{N}^{*}=\frac{k^{2}(a-b c)}{2 b\left(4 b I-k^{2}\right)}>0 \quad$ and $\quad \Pi_{S}^{*}-\Pi_{N}^{*}=$ $\frac{(a-b c)^{2} k^{2}}{4 b\left(4 b I-k^{2}\right)}>0$, we can see that both the market price and firm's profit are higher than the case without considering green sensitive consumer demand.

Taking the first derivative of (8) and (10) respect to green sensitivity $(k)$, we obtain $\frac{d p_{S}^{*}}{d k}=\frac{4 k I(a-b c)}{\left(4 b I-k^{2}\right)^{2}}>0$ and $\frac{d \Pi_{S}^{*}}{d k}=$ $\frac{2 k I(a-b c)^{2}}{\left(4 b I-k^{2}\right)^{2}}>0$. Thus, when the green sensitivity of consumers is enhanced, product price and the firm's profit are both increased.

Proposition 1 indicates that, when considering consumers' environmental consciousness, the firm should innovate to produce green products to meet the need of green consumers. Greening is not only beneficial for the firm, but also good for the society.

\section{ANAlysis Under both GREen SENSITIVE CONSUMER DEMAND AND GOVERNMENT SUBSIDY}

From the perspective of production, we assume government provides subsidies for green products. Therefore, the margin profit of the firm is $p-c+s$, where $c$ is the marginal cost of production and $s>0$ represents the per-unit subsidy paid by government resulting from the production of green product. We still suppose that the investment in the green innovation does not affect the per-unit cost of production. 
Based on the above model assumptions, the firm's profit function via green innovation is given by

$$
\Pi_{G}(p, g)=(a-b p+k g)(p-c+s)-I g^{2}
$$

The subscript $G$ denotes the case of considering both green sensitive consumer demand and government subsidy. We analyze the decision in two steps. First, the firm decides which degree of product to produce under government subsidies and green sensitive consumer demand, and then which price does the firm select to maximize his profit. Hence, this process is a two stage Stackelberg game.

\section{A. Optimal Price}

Given the firm's profit function, equating the first order conditions to 0 , we get proposition 2 referring to the firm's profit-maximizing price.

Proposition 2. Given green degree $\mathrm{g}$ of the product, the firm's optimal price is given below

$$
p_{G}^{*}(g)=\frac{a+k g}{2 b}+\frac{c-s}{2}
$$

Hence, (1) product price is decreasing in the government subsidy; (2) product price is increasing in the consumer sensitivity towards the green product.

Proof: Differentiating the profit $\Pi_{G}(p, g)$ with respect to $p$, we have

$$
\frac{\partial \Pi_{G}(p, g)}{\partial p}=-2 b p+b c-b s+a+k g
$$

The second order derivative of (11) with respect to $p$, we get $\frac{\partial^{2} \Pi_{G}(p, g)}{\partial p^{2}}=-2 b<0$. Hence, $\Pi_{G}(p, g)$ has a maximum. Let expression (13) equals 0 we obtain $p_{G}^{*}(g)=\frac{a+k g}{2 b}+\frac{c-s}{2}$.

Proposition 2 demonstrates, (1) under a certain green degree, we see that increased subsidy brings about a reduced price. As government subsidy is increased, the firm's marginal cost is decreasing relatively, which benefits both the firm and consumers. (2) Increasing consumer sensitivity towards green product results in an increased price. This happens because consumers are willing to pay more for the firm's product due to its green characteristic, and the firm can raise price to get more profit.

\section{B. Optimal Green Degree}

Substituting the value in the expression (12) for optimal price into the firm's profit function (11), we derive

$$
\Pi_{G}(g)=\frac{(a+k g-b c+b s)^{2}}{4 b}-I g^{2}
$$

Maximizing expression (14), we get proposition 3 referring to the firm's profit-maximizing green degree.

Proposition 3. The profit-maximizing level of green degree is given by $g_{G}^{*}=\frac{k(a-b(c-s))}{4 b I-k^{2}}$.

Proof: The first derivative of $\Pi_{G}(g)$ with respect to $g$ is

$$
\frac{d \Pi_{G}(g)}{d g}=\frac{k(a+k g-b c+b s)}{2 b}-2 I g
$$

Taking the second derivative, we get

$$
\frac{d^{2} \Pi_{G}(g)}{d g^{2}}=\frac{k^{2}}{2 b}-2 I
$$

The second derivative is negative when $4 b I>k^{2}$. It means that there is a maximum of $\Pi_{G}(g)$. Equating the first order condition to 0 we obtain $g_{G}^{*}=\frac{k(a-b(c-s))}{4 b I-k^{2}}$. Hence, we come to the conclusion that $g_{G}^{*}$ maximizes the profit.

Proposition 4. The green degree selected by the firm with government subsidy $\left(g_{G}^{*}\right)$ is higher than the case without $\left(g_{S}^{*}\right)$.

Proof: The minus between $g_{G}^{*}$ and $g_{S}^{*}$ is $g_{G}^{*}-g_{S}^{*}=$ $\frac{k s}{4 b I-k^{2}}>0$. It is straightforward to get $g_{G}^{*}>g_{S}^{*}$.

From proposition 4 , if green sensitivity is low $\left(4 b I>k^{2}\right)$, the firm will improve its green degree to a new level.

\section{CONCLUSION}

In this paper, we analyze the problems of firm's product green innovation when faces green sensitive consumer demand and government subsidy. We assume a linear demand model to investigate the influence of green sensitive demand and subsidy to green innovation. The results show that it is beneficial for the firm to consider green sensitive consumer demand. The firm can acquire more profit by production green innovation, and government subsidy can help the firm improve green degree to a higher level.

\section{ACKNOWLEDGMENTS}

This research was supported by University's Humanity \& Social Sciences Research Project of Jiangxi Province of China (No.JC1514).

\section{REFERENCES}

[1] Dangelico R M, Pontrandolfo P. From Green Product Definitions and Classifications to the Green Option Matrix. Journal of Cleaner Production, 2010, 18(16): 1608-1628.

[2] Kanchanapibul M, Lacka E, Wang X, et al. An Empirical Investigation of Green Purchase Behavior Among the Young Generation. Journal of Cleaner Production, 2014, 66(3): 528-536.

[3] Lai Ckm, Cheng Ewl. Green Purchase Behavior of Undergraduate Students in Hong Kong. The Social Science Journal, 2016, 53(1): 67-76.

[4] Liobikiene G, Mandravickaite J, Bernatoniene J. Theory of Planned Behavior Approach to Understand the Green Purchasing Behavior in the EU: a Cross-Cultural Study. Ecological Economics, 2016, 125(c): 38-46.

[5] Roberto R. Environmental Product Differentiation and Environmental Awareness. Environmental \& Resource Economics, 2007, 36(2): 237-254.

[6] Yakita A, Yamauchi H. Environmental Awareness and Environmental R\&D Spillovers in Differentiated Duopoly. Research in Economics, 2011, 65(3): 137-143.

[7] Chunlin Luo, Mingming Leng, Jian Huang, et al. Supply Chain Analysis under a Price-discount Incentive Scheme for Electric Vehicles. European Journal of Operational Research, 2014, 235(1):329-333.

[8] Jian Huang, Mingming Leng, Liping Liang, et al. Promoting Electric Automobiles: Supply Chain Analysis under a Government's Subsidy Incentive Scheme. IIE Transactions, 2013,45(8):826-844. 
[9] Ghosh D, Shah J. Supply Chain Analysis under Green Sensitive Consumer Demand and Cost Sharing Contract. International Journal of Production Economics,2015,164: 319 329.

[10] Swami S, Shah J. Channel Coordination in Green Supply Chain Management. The Journal of the Operational Research Society, 2013,64(3):336-351. 